\title{
Phaselis Su Sistemleri ve Hidrografisi Üzerine Genel Değerlendirme
}

\author{
General Assessment Concerning Water Systems and \\ Hydrography of Phaselis \\ Mehmet KÜRKÇÜ
}

open 2 access journals

PHASELIS: Disiplinlerarası Akdeniz Araştırmaları Dergisi'nde bulunan içeriklerin tümü kullanıcılara açık, serbestçe/ücretsiz "açık erişimli" bir dergidir. Kullanıcılar, yayıncıdan ve yazar(lar)dan izin almaksızın, dergideki makaleleri tam metin olarak okuyabilir, indirebilir, dağıtabilir, makalelerin çıktısını alabilir ve kaynak göstererek makalelere bağlantı verebilir.

PHASELIS: Disiplinlerarası Akdeniz Araştırmaları Dergisi uluslararası hakemli elektronik (online) bir dergi olup değerlendirme süreci biten makaleler derginin web sitesinde (journal.phaselis.org) yı boyunca ilgili sayının içinde (Volume I: Ocak-Aralık 2015) yayımlanır. Aralık ayı sonunda ilgili yıla ait sayı tamamlanır.

Dergide yayımlanan eserlerin sorumluluğu yazarlarına aittir.

Makale Künyesi M. Kürkçü, "Phaselis Su Sistemleri ve Hidrografisi Üzerine Genel Değerlendirme”. Phaselis I (2015) 69-79. DOI: 10.18367/Pha.15004

Kabul Tarihi: 26.02.2015 | Online Yayın Tarihi: 15.06.2015

Editörya Phaselis Research Project

www.phaselis.org 


\title{
Phaselis Su Sistemleri ve Hidrografisi Üzerine Genel Değerlendirme

\author{
General Assessment Concerning Water Systems and Hydrography of Phaselis
}

\author{
Mehmet KÜRKÇÜ*
}

Öz: Kuruluşu M.Ö. VII. yüzyılın başlarına tarihlenen ve üç doğal limanıyla Doğu Akdeniz ticaretinde önemli bir rol oynayan Phaselis kentinde en dikkat çekici yapılardan biri de ören yerinin girişinden itibaren görülebilen, kemerli suyoludur (aquaeductus). Phaselisliler kurdukları bu sistemle Roma Dönemi'nde kent içerisinde yüksek miktarlarda su gerektiren çeşme ve hamamlar inşa etmişlerdir. Kentte geçmiş dönemlerde gerçekleştirilen genel araştırmaların yanı sıra sadece suyollarını konu alan incelemeler de bulunmaktadır. Söz konusu çalışmalar herhangi bir kazı olmaksızın yüzeyde tespit edilen kalıntıların değerlendirilmesi ve sentezi sonucuna dayandırılmaktadır. Bu araştırma Phaselis kentinin su sistemleri ve hidrografisi üzerine bugüne kadar gerçekleştirilmiş tetkikleri, 2012 yılında başlayan ve halen devam eden yüzey araştırmalarının bulgularına göre değerlendirmeyi ve bu süreç boyunca gözlemlenen verilere göre yeni bir sentez sunmayı amaçlar. Çalışmada Phaselis kenti ile ilgili araştırmalar içerisinde yer alan su sistemleri üzerine yapılmış yorumların tamamı incelenip eleştirel düşünce ve objektif bakış açısıyla yeniden ele alınarak strüktürlerin günümüzdeki durumlarına göre nedenden sonuca giden bir perspektif ile analizleri yapılmaya gayret edilecektir.

Anahtar sözcükler: Phaselis · Su Kaynakları · Su Sistemleri · Suyolu (Aquaeductus) · Sarnıç

Abstract: One of the most remarkable structures inside the ancient city of Phaselis which was founded in the early VII. century B.C., and which played an important role in the Mediterranean trade due to its three natural harbours, is the vaulted waterway (aquaeductus) which can be seen from the site entrance. Due to the system established, the Phaselites were able to construct fountains and bath complexes which required large amounts of water, within the city in the Roman Period. In addition to the general research conducted in the past, there have been investigations that focus upon only the waterways. These aforementioned studies are based upon the results from the assessment and synthesis of only those ruins determined on the surface, without any excavations. This paper aims to assess the studies of the water systems and hydrography of Phaselis conducted to date, according to the finds from the surface explorations which began in 2012 and which continues today, and to present a new synthesis, taking into account the new data obtained within this process. Examining and reconsidering all of the comments made concerning the water systems within the research related to the city of Phaselis, with critical thinking and an objective view; the structures are analyzed from a cause and effect perspective, considering the current situations in respect to the evidence.

Keywords: Phaselis · Water Supplies · Water Systems · Waterway (Aquaeductus) · Cistern

Bu çalışma Phaselis kentinin su sistemleri ve hidrografisi üzerine bugüne kadar gerçekleştirilmiş çalışmaları 2012 yılında başlayan ${ }^{1}$ ve halen devam eden yüzey araştırmalarının bulgularına göre

* Dr., Université de Sorbonne, Paris. mhmtkurkcu@gmail.com

1 Phaselis Yüzey Araştırmaları, Akdeniz Uygarlıkları Araştırma Enstitüsü Müdürü Prof. Dr. M. ARSLAN yöneti- 


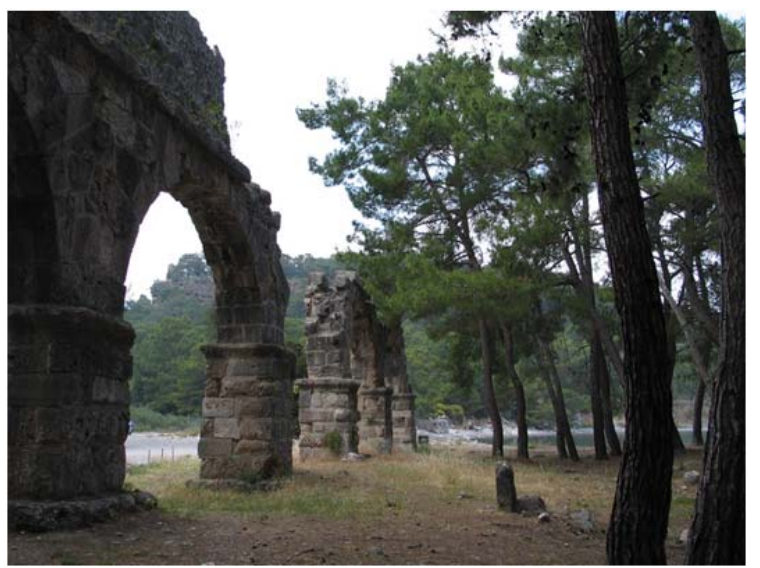

Fig. 1

değerlendirmeyi ve bu süreç boyunca gözlemlenen verilere göre yeni bir sentez sunmayı amaçlar. Çalışmada Phaselis kenti ile ilgili araştırmalar içerisinde yer alan su sistemleri üzerine yapılmış yorumların tamamı incelenip eleştirel düşünce ve objektif bakış açısıyla yeniden ele alınarak strüktürlerin günümüzdeki durumlarına göre nedenden sonuca giden bir perspektif ile analizleri yapılmaya çalışılacaktır.

Kalıntıların Phaselis'e ait olduğunu, kente gerçekleştirdiği 1811 yılındaki ziyaretinde tespit eden F. Beaufort kitabının ören yeriyle ilgili bölümünde ${ }^{2}$ suyolunun (aquaeductus) sadece kent içinde gördüğü kısımlarından ve su kemerlerinden (Fig. 1) bahsetmektedir.

Phaselis'te 1968 yılında H. Schläger'in başlattığı ilk detaylı ve bilimsel araştırmalar, kendisinin 1969 yılında geçirdiği kaza sonrası yaşamını kaybetmesi sebebiyle J. Schäfer tarafından tamamlanmış ve sonuçları içerisinde su sistemlerine ayrılan bir bölümün de yer aldığı bir kitap halinde yayımlanmıştır. Araştırmacı kentin su ihtiyacının her dönemde hem sarnıçlarla hem de kente taşınan sularla sağlandığını ${ }^{3}$, kuzey yerleşim olarak adlandırdığı alanın tanımını yaparken burada bir kaya tapınağı ile bir zamanlar suları bol olan bir mağara bulunduğunu ${ }^{4}$ (Kaynak Mağarası), Phaselislilerin su intiyaçlarını karşılamak için erken dönemlerden itibaren bu kaynaktan (Fig. 2) yararlandıklarını belirtir. Araştırmacıya göre, söz konusu kaynaktan elde edilen sular kuzey (Hellenistik) yerleşimden kent merkezine kadar olan mesafeyi kemerler üzerine yerleştirilen borularla katetmişlerdir.

Araştırmacının ele aldığı bir diğer su yapısı da su kemerlerinin kuzey başlangıç noktasından yaklaşık $680 \mathrm{~m}$. kuzeydoğuda bulunan ve ana kayanın traşlanmasıyla şekillendirilip oluşturulan bir rezervuardır (Fig. 3).

D. J. Blackman 1973 tarihli Phaselis Limanları başlıklı çalışmasında ${ }^{5}$ su kemerinden bahseder. Blackman'a göre de, bir bölümü sur duvarı üzerinde bulunan bu suyolu kuzeyde, tepedeki bir 'kaynak'tan elde edilen suları kente taşıyordu.

Kentteki ilk kazılar 1980 yılında, Güney Antalya Turizm Gelişim Projesi kapsamında, Turizm ve Tanıtma Bakanlığı'nın koordinatör-

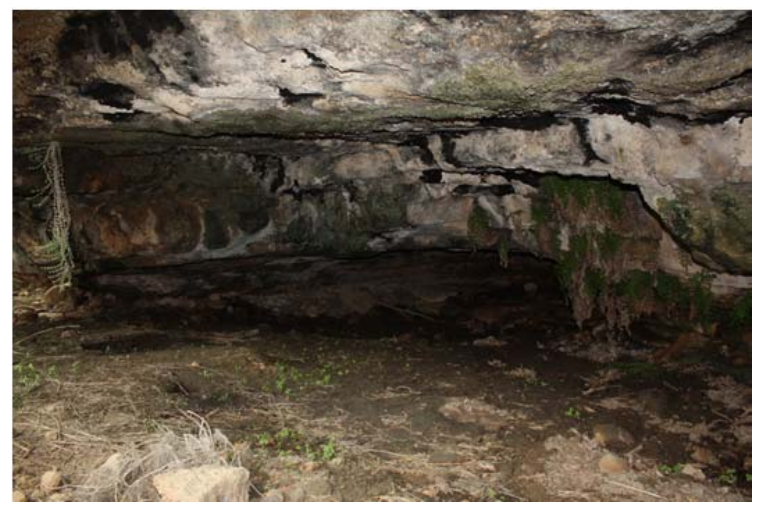

Fig. 2

mindeki disiplinlerarası bilim insanlarından oluşan bir ekip tarafından yürütülmektedir.

Beaufort 1818, 60-61.

Schäfer 1981, 42.

Schäfer 1981, 30.

Blackman 1973, 358.

Dörtlük 1981, 80. 


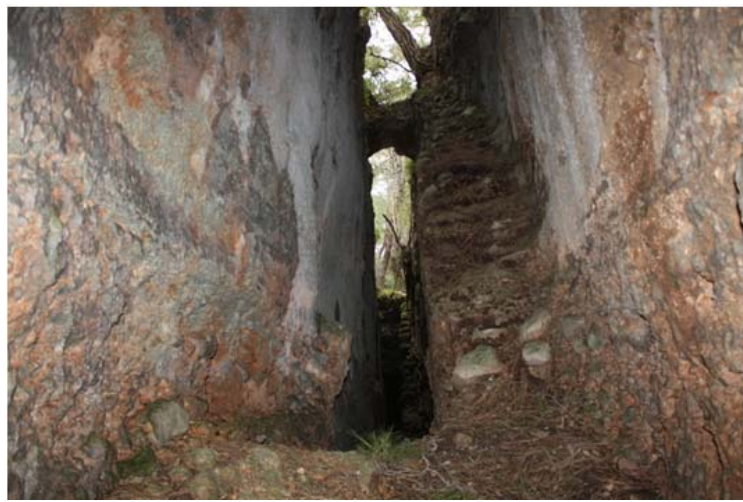

Fig. 3

lüğünde, daha çok arkeolojik alan düzenlemesi ve yanaşma iskelesi inşa ederek 1982 yılına kadar örnek bir ören yeri yaratma düşüncesiyle, kentin turizme kazandırıması amacına yönelik olarak arkeolog K. Dörtlük başkanlığında bir ekip ile başlamıştır.

1982 yılında kazı ve onarım çalışmalarının tarafından yürütülmesine karar verilip devredildiği Prof. Dr. C. Bayburtluoğlu'nun 1982, 1983 ve 1984 yıllarında, kısıtlı bir süre içerisinde, zamanının şartlarına ve tüm olumsuzluklara rağmen kent içerisinde gerçekleştirdikleri Phaselis araştırmaları tarihinde büyük öneme sahiptir.

Kazı raporları incelendiğinde kentte 1980 yılında başlayan bu çalışmaların esas olarak "liman caddesinin her iki tarafında bulunan yapıların kısa sürede ortaya çıkarılmasını" hedeflediği görülür.

1982 yılındaki kazılar ve sonuçlarının yer aldığı raporda suyla ilgili düzenlemeler üzerinde de gözlemlerde bulunulduğu anlaşılmaktadır ${ }^{8}$ : Kazı başkanı kent merkezine kemerlerle ulaşan suların bir kısmının agoranın güney duvarında açılan oyuklara yerleştirilen künklerle meydan seviyesine inip oradan da agora duvarına paralel olarak kuzeye doğru devam ettiğini ve bu boruların agoranın kapısı önünde, korunmuş durumda olduklarını aktarır. Söz konusu düzenlemeden günümüze sadece duvardaki oyuklar kalmıştır (Fig. 4).

Bir diğer gözlem ise, Tiyatro Hamamı güney duvarı üzerindeki çeşme ile güneybatı köşesindeki soğuk su girişidir.

Antikçağda kurulan kentlerin su sistemleri incelenirken atık sular ile yağmur sularının şehir dışına taşınması da kesinlikle inmal edilmemesi gereken bir konudur. Kentte yıkım, sel ve taşkınlara yol açabilecek yağışlar ile salgın ve hijyen sorunu yaratabilecek kullanıımış ve atık suların tahliyesi için yapılan düzenlemeler en az kente su sağlayan strüktürler kadar önemli olduğundan birlikte incelenmeleri sistemin tümünün daha iyi ve kolay anlaşımasını sağlayacaktır. Bu durum göz önünde bulundurulduğunda Bayburtluoğlu'nun mozaik döşemeli, giriş ve çıkışları Tiyatro Hamamı ve tam karşısındaki duvarda bulunan karşılıklı iki kapıyla sağlandığı dikdörtgen planlı bir yapıyı, kent içindeki konumu ve mimari özelliklerinin yanı sıra pis su kanalına bağlanan oldukça büyük bir kanala sahip olması nedeniyle latrina olarak tanımlaması ${ }^{9}$ ileride su sistemleri üzerinde yapılacak araştırmaların bu perspektif doğrultu-

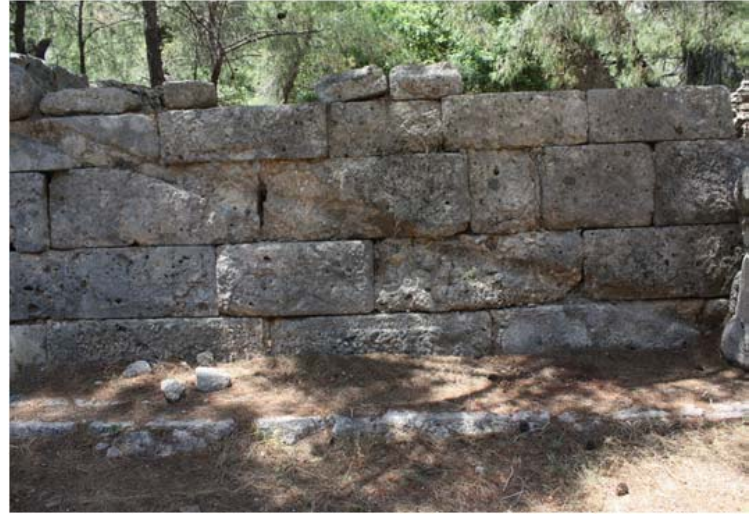

Fig. 4

\footnotetext{
Bayburtluoğlu 1984, 302.

Bayburtluoğlu 1983, 183-184.

Bayburtluoğlu 1983, 187.
} 
sunda, su temini ve tahliyesinin bir bütün olarak incelenmesinin gerekliliğini göstermesi açısından iyi bir örnektir.

Bayburtluoğlu, Phaselis kentinde 3 yıl süren çalışmalarının son dönemini kapsayan raporunda ${ }^{10}$ Hadrianus Agorası'nın kuzey ve doğu kenarlarının bilhassa Doğu Roma Dönemi'nde uğradığı yoğun değişiklikleri yine burada yaptıkları temizlik sonrası ortaya çıkan "agora yüzeyinden giden su kanalları" ile doğrulamaktadır.

Küçük Asya'daki Roma suyollarını inceleyen J. J. Coulton'un da Phaselis suyolunu Schäfer'in yazdıklarına dayanaraktan yanlış yorumladığı görülür ${ }^{11}$. Araştırmacıya göre, istisnai bir duruma sahip olan Phaselis'te, kaynağı kent merkezine yarım kilometre uzaklıkta olmasına rağmen sular, bu kadar kısa bir mesafeyi büyük bir kısmı kemerler üzerinde inşa edilen suyolu sayesinde katetmekteydi.

Bir süre kesintiye uğrayan kazılara daha sonra, 1991 yılında, Antalya Arkeoloji Müzesi tarafından yeniden başlansa da bu çalışmalar daha çok ot ve bitki temizliği ağırlıklı olmuştur. 1992 yılında yapılan çalışmaların sunulduğu raporda" ${ }^{12}$ su sistemleri ile ilgili olarak sadece "A limanı ile askeri liman arasındaki burun üzerinde yer alan sarnıçlı büyük yapı" ifadesine yer verildiği görülür.

İlk defa 1994 yılında G. Büyükyıldırım, Antalya bölgesinde bulunan tarihi su yapılarını incelediği kitabında ${ }^{13}$ Phaselis'e gelen suyun kaynağı olarak Tahtalıdağ eteklerindeki Tamtır Alanı'nı gösterir ve Atamak Sırtı eteklerinde, denizden $7 \mathrm{~km}$. uzaklıkta, $1000 \mathrm{~m}$. yükseklikte 3 noktadan kaynayan pınarlar olduğunu, bunlardan birinin Silma Pınarı diye adlandırıldığını, kente çok büyük bir eğimle (ortalama \%10) su sağlayan auqaeductus'un ise en az $10 \mathrm{~km}$. uzunlukta olduğunu belirtir.

Söz konusu araştırma Phaselis kentine su sağlayan kaynaklar hakkında içerisindeki sınırlı bilgilere rağmen en verimli çalışma olarak kabul edilebilir. Büyükyıldııım'ın bu kitabı aynı zamanda daha sonraki yıllarda yapılan araştırmalar için önemli bir kaynak ve referans olmuştur.

Kentin su sistemleri üzerine 1996 tarihli "Phaselis Tarihsel Su Iletimi"14 başlıklı bir Yüksek Lisans çalışması bulunmaktadır. İçerisinde, Phaselis su sistemleri hakkındaki bilgiler, görseller dışında sadece bir kaç sayfaya sığdııımış bu araştırma günümüzde artık görülemeyen, kemerler üzerine yerleştirilmiş pişmiş toprak boruların belgelenmiş olması açısından ilginçtir.

C. Bayburtluoğlu'nun 2004 yılında Lykia ve kentleri üzerine yazdığı kitabın Phaselis'e ayrılan bölümünde ${ }^{15}$, üzerinde akropolis'in kurulduğu yarımadada çok sayıda piriform (armut tipli) sarnıç bulunduğu, içlerinden Zeus Boulaios Tapınağı'nın batı, kuzeybatı eteğinde düzenlenenin yapısı, çapı ve ağzındaki $6 \mathrm{~m}$. uzunluğundaki yekpare iki bloğuyla diğerlerinden ayrıldığı yer almaktadır.

Zeus Boulaios Tapınağı'nın lokalizasyonu, bu alanda günümüze değin herhangi bir kazı çalışması yapılmaması, arazinin çok sık bitki örtüsüyle kaplı olması ve yapılan yüzey araştırmaları sürecinde uygulanan ot ve bitki temizliğinin yarımadanın güneybatı köşesinde bulunan, alan

10 Bayburtluoğlu 1984, 375.

11 Coulton 1987, 76.

12 Atila et al. 1984.

13 Büyükyıldırım 1994, 80-83.

14 Ümit 1996.

15 Bayburtluoğlu 2004, 86. 
tarama ve tanımlaması yapılan Doğu Roma Dönemi dini yapısıyla (bazilikal kilise) sınırlı kalması gibi farklı nedenlerden dolayı kesin olarak saptanamamıştır. Akropolis'in bulunduğu yarımadada 2014 yılı araştırmaları neticesinde tespit edilen sarnıç sayısı 14 adede ulaşmış olsa da gereken temizlik çalışmaları yapıımadan söz konusu sarnıcın bu grup içerisinde yer aldığını söylemek henüz mümkün değildir. Aynı bölüm içinde Domitianus ve Hadrianus agoraları arasından geçerek caddeye bağlanan sokağın her iki tarafındaki yalaklı, tek katlı ve sütunlu bir cepheye sahip "anıtsal iki nymphaion" yapısından bahseden Bayburtluoğlu bunlardan Hadrianus Agorası'na bitişik olarak inşa edileni, su künklerinin agoranın duvarına sonradan yerleştirilmeleri nedeniyle M.S. II. yüzyılın ikinci yarısına tarihlese de yapının daha önceki olası evrelerinin yapılacak kazılarla ortaya çıkabileceği olasılığını da göz ardı etmemektedir. Bunun yanında Liman Caddesi'nin alt yapısının bulunduğu bölümde ${ }^{16}$ caddenin her iki yanındaki yapıların (bilhassa Tiyatro Hamamı ve latrina) atık suları ile yağmur sularının tahliyesi için düzenlenen kanalizasyon şebekesini burada yeniden ele aldığı görülür.

2008 yılında tamamlanan "Batı Akdeniz (Likya) Tarihi Yerleşim Merkezlerinin Su Iletim Sistemlerinin Hidrolik Açıdan Incelenmesi" başlıklı bir diğer Yüksek Lisans tezi içerisinde yine sınırlı ölçüde Phaselis su sistemlerine değinildiği, daha önceki Yüksek Lisans çalışması içerisinde yer alan açıklamaların tekrarlandığı, bunlardan farklı olarak suyun tahmini debisi ve miktarını dayanak almak gibi pek güvenilirliği olmayan bir yöntemle ${ }^{17}$ kentin nüfusunu hesaplamaya yönelik denemelerde bulunulduğu görülür.

2008 yılında "Phaselis Antik Kenti ve Teritoryumu" başlıklı doktora tezinin "Su Temini" bölümünde ${ }^{18}$ Phaselis kentinin su sistemleri hakkında genel bir değerlendirmede bulunan N. Tüner Önen, kentte 2012 yılında başlayan ve halen devam eden yüzey araştırmaları kapsamında; 20122014 yılları arasında "Phaselis Antik Kenti ve Teritoryumunun Epigrafik ve Hidrografik Araştırma Projesi" konulu bir çalışma gerçekleştirmiş ve sonuçlarını A. Akçay ile birlikte bir makale ${ }^{19}$ olarak yayınlamıştır. Yukarıda sözü geçen, ana kayanın içerisinde düzenlenen rezervuar yapısının son durumu bu makale içerisinde detaylıca ele alınmıştır.

\section{Değerlendirme}

Yaşamsal ihtiyaçların başında gelen su antikçağda kurulan ve içerisinde yeterli miktarlarda su kaynağı olmayan kentlerde öncelikle sarnıçlarla daha sonraları ise suyolları (aquaeductus) inşa edilerek karşılanmıştır. Başlangıçta içerisinde yağmur sularının biriktirildiği sarnıçların kentteki su ihtiyacının çeşitli nedenlerle artması sonucu, bu ihtiyacı karşılamak ve kente su getirmek amacıyla kurulan aquaeductus'lar sonrasında da işlevlerini kaybetmedikleri; hatta özellikle kamu sarnıçlarının fistula ile söz konusu suyollarına bağlanıp bunların sağladığı sularla beslendikleri epigrafik ve arkeolojik verilerle belgelenmiştir ${ }^{20}$.

Phaselis kenti üzerine günümüze değin gerçekleştirilen çalışmalar incelendiğinde su sistemleri konusundaki değerlendirmelerin, G. Büyükyıldııım'ın Tantır Alanı ve civarındaki kaynak/ları belirlediği 1994 yılına kadar aynı yönde geliştiği, oluşan ortak kanıya göre akropolis'teki sarnıçların yanı sıra kente suyun Kuzey Yerleşim olarak adlandırılan tepedeki bir kaynaktan (Kaynak Mağarası) sağlandığı düşüncesinin genel kabul gördüğü anlaşılmaktadır.

\footnotetext{
Bayburtluoğlu 2004, 91.

Kürkçü 2014, 353-356.

Tüner Önen 2008, 79-83.

19 Tüner Önen - Akçay 2014

20 Dessales 2013, 225-241.
} 


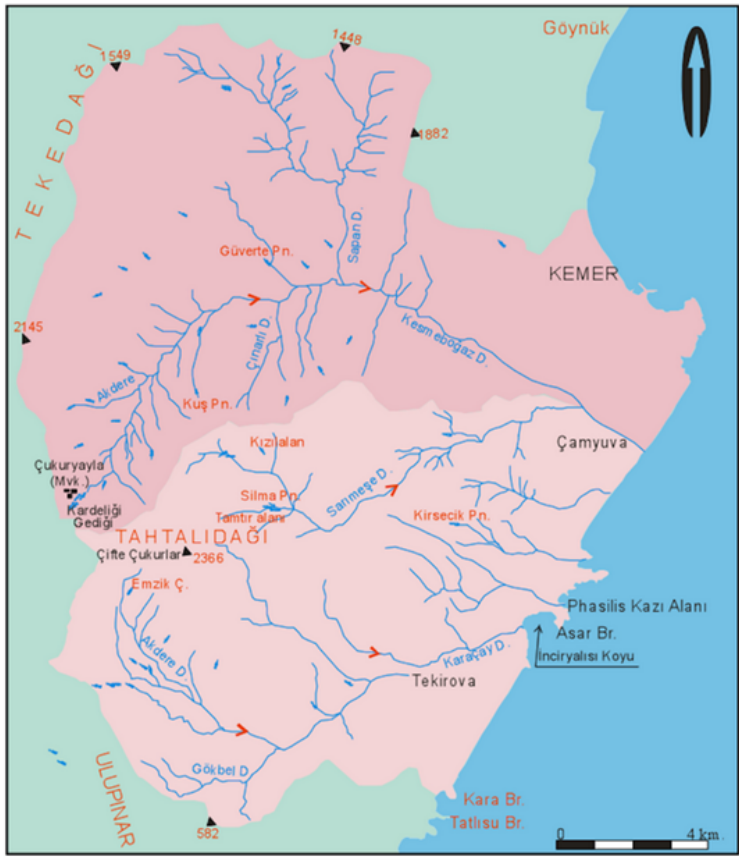

Fig. 5

Bu tarihten sonra Phaselis'te su temini konusunda çalışan araştırmacılar Tamtır Tepesi (Fig. 5) ve Atamak Sırtı eteklerinde 3 noktada kaynayan pınarlardan gelen suların Molla Deliği olarak bilinen dar kayalıklar arasından itibaren Çatak, daha aşağılarda da Sarımeşe deresi adını aldıklarını belirleyip suyolunun Molla Deliği'nden sonra dere yatağından ayrılmış olabileceğini ve Kovanlık Sırtları'ndan Phaselis'e doğru yönelmesi gerektiğini ifade ederler. Kentin bu kesiminde günümüze değin arkeolojik bir kazı gerçekleşmediğinden söz konusu hipotetik yaklaşımları yerinde görmek ve değerlendirmek amacıyla Kaynak Mağarası adı verilen alanda yaptığımız incelemelerde herhangi bir su kaynağına rastlanmamıştır.

Schäfer'in kente su ihtiyacının her dönemde hem sarnıçlarla hem de su kanallarıyla aktarılan taze sularla sağlanmış olması savı ise kısmen doğrudur. İlk dönemlerde evlerin içerisinde bir oda, avlu ya da domus aralarında bir alana yerleştirilen sarnıçlarda toplanan sular ihtiyacı karşılamaya yeterli olurken daha sonraları kentsel, demografik ve hijyenik gelişmelere paralel olarak artan su kullanımı sonucunda başka kaynak arayışları kendini gösterir.

Antik kaynaklara göre ${ }^{21}$ (Mela I. 14) kuruluşu M.Ö. VII. yüzyıl başlarına tarihlenen Phaselis'te ilk yerleşim yarımada üzerinde (akropolis) olup zamanla aşağılara inilmiş ve şehircilik çalışmalarına başlanmıştır.

Antikçağda bilinen ilk suyollarına verilecek en güzel örneklerden biri M.Ö. VıII. yüzyıla tarihlendirilmektedir ${ }^{22}$. Asur kralları kimi zaman yeni kentler yaratarak kimi zaman da daha önceden var olanları kraliyet merkezleri için yeniden organize ederek birçok kez başkentlerinin yerini değiştirmişlerdir. Kentte yaşayanların su ihtiyacının karşılanması ve bahçe ve tarlaları sulamak amacıyla civardaki nehirlerden ya da dağlardaki kaynaklardan su getirilmesi bu dönüşümler sürecinde inşa edilen kanallar sayesinde mümkün olmuştur. İçerisinde nehir ve kanal adı geçen M.Ö. I. binyıl Asur metinlerinden özellikle II. Sargon (M.Ö. 721-705) ve oğlu Senakherip (M.Ö. 704-681) dönemlerine ait belgeler dikkat çekicidir ${ }^{23}$. Bunlardan, Ninova'yı başkent seçen II. Sargon'un oğlu Senakherip'in su projesi, uzunluğu 150 km.'yi bulan kanallar, tüneller ve su kemerleri ile barajları kapsamaktadır.

Orijinleri Bronz Çağı'ndan itibaren Mezopotamya ve Mısır medeniyetlerine kadar uzansa da, günümüzde kalıntıları görülen anıtsal suyolları denince akla ilk olarak Romalılar gelmektedir. Özellikle M.Ö. I. yüzyılda, Agrippa'nın Roma'da aedilis'lik görevini ifa ettiği tarihlerde önceliği kente su sağlamaya vermesi, bu amaçla daha önceden var olan kanalları onarttırması ve yenilerini inşa ettirmesi sonucu, başkentte ve ardından da imparatorluğun farklı bölgelerinde yaygın-

\footnotetext{
21 Romer 1998, 57.

22 Bagg 2000, 316.

23 Duymus Florioti 2012, 152.
} 
laşmaya başlamışı ır ${ }^{24}$. Elbette bu etkenlerin yanında opus caementicium'un keşfi ve tonoz ve kemer yapımındaki ilerlemeler bu yaygınlaşmayı hızlandırmış, bu dönemden itibaren inşa edilen suyollarıyla imparatorluk sınırları içerisindeki kentlere çok daha uzak mesafelerden su getirilmesini mümkün kılmıştır.

Suyollarının kente su sağlamak dışında bir diğer önemli fonksiyonu da imparatorluğun gücünü sergilemektir. Frontinus'un Roma kenti'nin suyolları üzerine yazdığı eserin (De Aquaeductu Urbis Romae) düzenlemelerini ve çe-

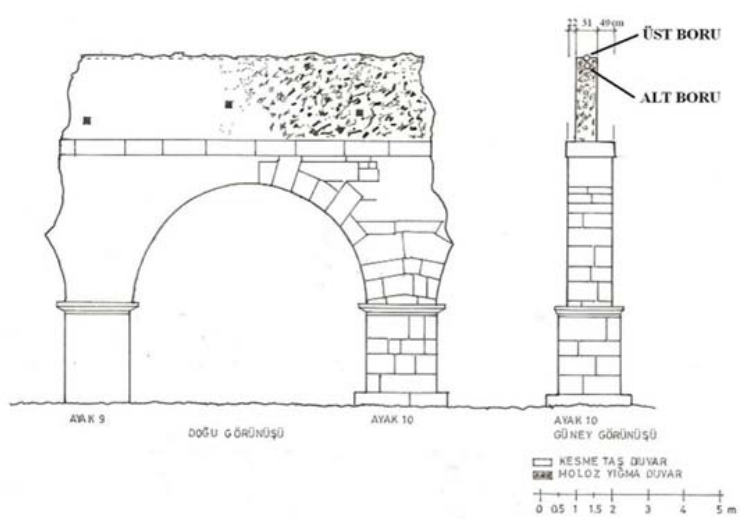

Fig. 6 virisini yapan P. Grimal'in bu konu ve yazarı hakkında yaptığı yorumlar ilgi çekicidir. Grimal, Frontinus'un kitabının her şeyden önce politik bir doküman olduğunu, bir kaç sene sonra yazılan Genç Plinius'un panegyricus'u gibi propaganda edebiyatı içerisinde yer aldığını, yeni rejimin Romalıların sağ|ıklı yaşamalarına ve güvenliklerine önem verdiğini göstermeye yönelik olduğunu ve bu nedenlerden ötürü Frontinus'un sadece princeps'in sözcülüğünü yapmaya soyunduğunu vurgular $^{25}$.

Phaselis kentinin su ihtiyacının kuruluşundan itibaren (M.Ö. VII. yüzyıl) kanallar ya da suyolları ile karşılandığını gösteren arkeolojik ya da epigrafik hiç bir veri bulunmamaktadır.

Yukarıda sözü edilen nedenlerden ötürü, Schäfer'in iddia ettiği gibi, kentin su ihtiyacı kurucuları ya da ilk yerleşenler tarafından yapılmış herhangi bir suyolu ile değil de daha çok sarnıçlar ve gölden ${ }^{26}$ sağlanan sularla karşılanmış olmalıdır.

Suyun taşındığı kanalların üzerine yerleştirildiği duvar yaklaşık $2 \mathrm{~m}$. yüksekliğe eriştiğinde kemer (opus arcuatum) inşa etmek daha özenli bir çalışma gerektirse de kullanılacak malzeme miktarı yarı yarıya azalı ${ }^{27}$. Yine İmparatorluk Dönemi'nde iki ya da daha fazla suyolunun aynı güzergâhı izledikleri ve hidrolik seviyesinin de uygun olduğu durumlarda, iki ya da üç kanal aynı kemerler üzerinde üst üste yerleştirilip inşaat giderleri önemli ölçüde düşürülürdü ${ }^{28}$. Phaselis'e su sağlayan aquaeductus hem kemerler üzerinden geçip kente ulaşmakta hem de üst üste yerleştirilmiş iki kanal barındırmaktadır (Fig. 6). Bununla birlikte kesin bir tarihlendirme yapabilmek için elimizde mimari özellikleri dışında herhangi bir veri bulunmamaktadır. Benzer örnekleriyle karşılaştırıp göreceli bir tarihlendirme yoluna gidilmesi, ayakta kalan bölümler üzerinde gözlemlenen onarımlar nedeniyle pek güvenilir olmayacaktır.

Kent içerisinde ve hinterlantında 2014 yılı araştırma sezonu içerisinde saptanan sarnıçlar ise, genelde sınırlı depolama kapasitesine sahip olup şahsi kullanım amaçlı olmalıdır. Bunlardan kamu yapılarında, tetragonal agora (enlem: 36,523950, boylam: 30,551930, yükseklik: $1 \mathrm{~m}$.) ve yarımadanın güneybatısındaki dini yapı (bazilikal kilise) içerisinde (enlem: 36,520984, boylam: 30,551269, yükseklik: 27 m., hassasiyet 5 m.) bulunanlar diğerlerine oranla daha büyük hacme

24 Roddaz 1984, 148.

25 Grimal 1944, XVI.

26 G. Bean ise, erken dönemlerde gölden yararlanılamaması durumunda yağmur suyunun biriktirildiği sarnıçlara bağımlı kalınmış olunabileceğini belirtir.

27 Leveau 1979, 8-19.

28 Bonnin 1984, 185. 


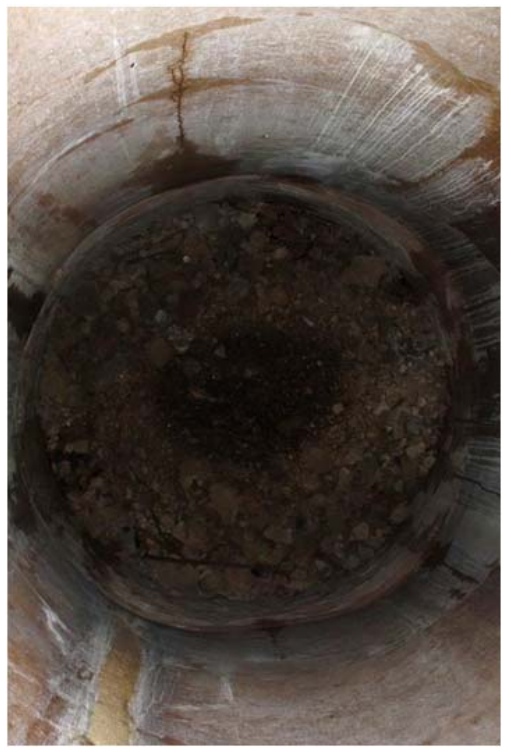

Fig. 7

sahiptirler.

Aralarında en iyi durumda korunagelen kilise içerisinde inşa edilmiş olanıdır (Fig. 7). Tabanı moloz ve toprak kaplı (AKRS 2) bu yapının zemin seviyesinde çapı yaklaşık 7,97 m.'dir. Rezervuar bölümünün üzeri kaplı zeminden itibaren yüksekliği 9,65 m. olup bu da yaklaşık $50 \mathrm{~m}^{3}$ hacme denk gelmektedir. İçerisi üzerini örten blokların üst seviyesine kadar kırmızımsı renkli hidrolik bir sıvayla kaplıdır. Bu sarnıç silindirik yapısıyla kentlerde sıklıkla rastlanan, içerisinde bulunan suyun ısınıp buharlaşmasını önlerken aynı zamanda kirlilik ve kazalara karşı üzerini örtme kolaylığı sağlayan, yukarıya çıktıkça daralan klasik şişe ya da piriform (armut tipli) sarnıçlardan ayrılır. Sarnıcın üstü, ortada 0,42 m. genişliğinde, 1,17 m. uzunluğunda bir açıklık bırakacak şekilde kuzey-güney istikametinde yerleştirilen ortogonal bloklarla örtülmüş bunların üzerine de iç ve dış kenarları dikdörtgen formunda, özenle tıraşlanmış, çerçeveyi andıran, kısmen kırılmış bir kaya bloğu

yerleştirilmiştir. 1,82 m. uzunlukta ve 0,71 m. genişlikteki bu bloğun sağlam olan batı kenarının yüksekliği $20 \mathrm{~cm}$., kalınlığı ise $15 \mathrm{~cm}$.'dir. Kuzey ve güney kenarlarda genişlik $32 \mathrm{~cm}$. ölçülmüştür.

Sarnıcın 1,78 m. kuzeyinde ortasından ikiye kırılmış, 1,24 m. uzunluğunda 0,66 m. genişliğinde kayaya oyulmuş dörtgen bir tekne (Fig. 8) bulunmaktadır. Güneybatı köşesinin üzerinde, yüzeyde yuvarlak bir yuva açılmıştır. Teknenin tabanında, güney kenarına $3,5 \mathrm{~cm}$. genişliğinde bir kanal açıldığı, hemen yanına da $20 \mathrm{~cm}$. çapında birkaç cm derinliğinde bir çukur oyulduğu gözlemlenmiştir. Kısa kenarlarının biçimi ve iç kısmında (kuzeyde) bulunan basamak ile Anadolu'da Bergama $^{29}$, Perge $^{30}$ ve Termessos'ta ${ }^{31}$, Yunanistan'da Arkadya Bölgesinde ${ }^{32}$, Lykaion'daki hipodrom yakınında bulunan örneklerden ayrılmaktadır. İç kısımda güney kenar köşeleri yuvarlatılmış ve oval bir biçim kazandırılmışken kuzey kenarı düz ve köşeli olarak biçimlendirilmiştir.

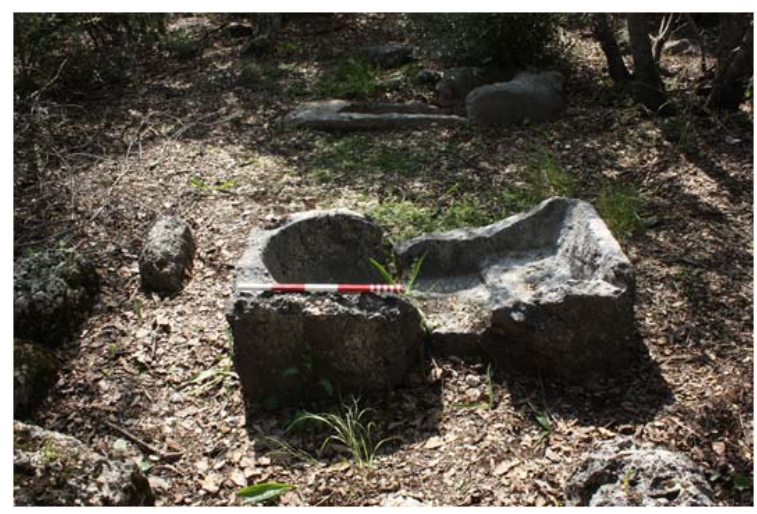

Fig. 8

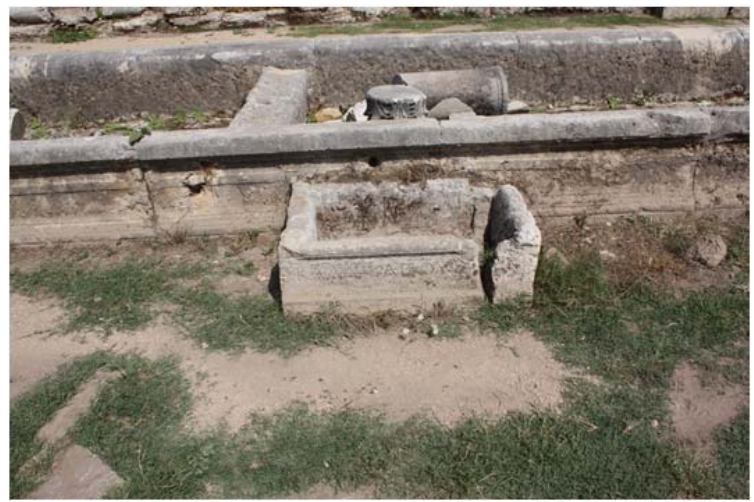

Fig. 9

29 Brinker 1990, 53.

30 Dorl-Klingenschmid 2001, 112.

31 Kürkçü 2014, 219-222.

32 Daremberg - Saglio 1881, 1229. 
Diğer kentlerde rastlanan örnekler (Fig. 9) bulundukları yer nedeniyle (daha çok çeşme, gymnasion ya da kanal kenarında), susuzluk gidermek, temizlik (vücut ve mekân) ve hayvanları sulamak gibi günlük su ihtiyacını karşılamaya yöneliktir.

Bazilikal kilise içerisinde saptadığımız bu monolit tekne bulunduğu kontekst içerisinde değerlendirildiğinde diğerlerinden farklı olarak, vaftiz teknesi işlevi görmüş olabileceği akla gelmektedir. Vaftiz, Hıristiyan inancına göre günahların affının bir göstergesidir. Aziz Paulus'un Romalılara mektuplarında ${ }^{33}$ Issa ile ölümde ve dirilişte bütünleşmek, onunla birlikte ölmeyi ve dirilmeyi kabul etmek olarak tanımlanan ${ }^{34}$ ve bir dönem havuzlarda yapılan söz konusu ritüel daha sonraları ölülerin içerilerine yerleştirildikleri lahitleri sembolize eden bu tip teknelerde yapılmaya başlanmıştır.

Gelecek yıllarda yarımada üzerinde yapılacak kazı çalışmaları sonrasında elde edilecek veriler, günümüz itibarıyla işlevi kesin olarak bilinmese de suyla bağlantısı hakkında en ufak bir şüphe olmayan bu strüktürün gerçek kullanım amacının saptanmasına aynı zamanda akropolis yerleşmesi sarnıçlarının tipokronolojisinin çıkarılarak bu alanda büyük bir boşluğun doldurulmasına imkân sağlayacaktır. 


\section{BíBLIYOGRAFYA}

\section{Antik Kaynaklar}

Paul. epist. ad. Rom.

\section{Modern Literatür}

Atila et al. 1994

Aydın 2006

Bagg 2000

Bayburtluoğlu 1983

Bayburtluoğlu 1984

Bayburtluoğlu 2004

Beaufort 1818

Blackman 1973

Bonnin 1984

Brinker 1990

Büyükyıldırım 1994

Coulton 1987

Daremberg - Saglio 1881

Dessales 2013

Dorl-Klingenschmid 2001

Dörtlük 1981

Duymuş Florioti 2012

Grimal 1944

Kürkçü 2014

Leveau 1979

Roddaz 1984

Romer 1998
(= Paulus Apostolus, Epistolae ad Romanos).

Kullanılan Metin : Paulus Apostolus, Epistola Sancti Pauli Apostoli ad Romanos. Ed.: S. de Brais. Lipsiae 1726.

A. I. Atila, S. B. İzgiz - B. Karakurt, "1992 Yılı Phaselis Çevre Düzeni ve Temizlik Çalışmaları". Ed. T.C. Kültür Bakanlığı Anıtlar ve Müzeler Genel Müdürlügü, IV. Müze Kurtarma Kazıları Semineri, 26-29 Nisan 1993 Marmaris. Ankara (1994) 429-456.

A. Aydın, "Kilikya ve İsaurya Bölgesi Vaftiz Yapıları". Sanat Tarihi Dergisi XV/1 (2006) 1-19.

A. M. Bagg, "Irrigation in Northern Mesopotaia: Water for the Assyrian Capitals $\left(12^{\text {th }}-7^{\text {th }}\right.$ centuries BC.)". Irrigation and Drainage Systems 14/4 (2000) 301-324.

C. Bayburtluoğlu, "Phaselis'teki Çalışmalar ve Çevre Araştırmaları ". KST V (1983) 181-191.

C. Bayburtluoğlu, "1983 Phaselis Kazı Raporu". KST VI (1984) 301-312.

C. Bayburtluoğlu, Likya. İstanbul 2004.

F. Beaufort, Karamania or A Brief Description of the South Coast of Asia Minor. London 1818.

D. J. Blackman, "The Harbours of Phaselis". The International Journal of Nautical Archaeology and Underwater Exploration 2/2 (1973) 355-364.

J. Bonnin, L'eau dans l'Antiquité. Paris 1984.

W. Brinker, Wasserspeicherung in Zisternen : Ein Beitrag des Wasserversorung früher Städte (Mitteilungen des Leichweiss-Instituts für Wasserbau der Technischen Univesität Braunschweig, 109). Braunschweig 1990.

G. Büyükyıldırım, Antalya ve Çevresi Tarihi Su Yapıları. Ankara 1994.

J. J. Coulton, "Roman Aqueducts in Asia Minor". Eds. S. Macready - F. H. Thompson, Roman Architecture in the Greek World. London (1987) 72-84.

C. Daremberg - E. Saglio, Dictionnaire des Antiquités grecques et romaines. Paris-Hachette 1881.

H. Dessales, Le Partage de l'eau: Fontaines et Distribution Hydraulique dans I'habitat Urbain de I'Italie Romaine. Rome 2013.

C. Dorl-Klingenschmid, Prunkbrunnen in kleinasiatischen Städten. Funktion im Kontext. Munich-Pfeil 2001.

K. Dörtlük, "1980 yılı Phaselis Arkeolojik Çalışmaları”. KST IV (1981) 80-82.

H. H. Duymuş Florioti, "Mesopotamia River Transport in the $1^{\text {st }}$ Millennium B.C.: The Assyrian's Case". History Studies: International Journal of History 4/4 (2012) 147-159.

P. Grimal, Frontin, Les Aqueducs de la Ville de Rome. Texte établi, Traduit et Commenté. Paris 1944.

M. Kürkçü, L'urbanisme et les Aménagements Hydrauliques de Termessos. Yayınlanmamış Doktora Tezi, Université de Paris-Sorbonne. Paris 2014.

P. Leveau, "Les Techniques de Construction des Aqueducs". Dossiers de l'Archéologie 38 (1979) 8-19.

J. M. Roddaz, Marcus Agrippa. Paris 1984.

F. E. Romer, Pomponius Mela's Description of the World, De Chorogra- 
Schäfer 1981

Tüner Önen - Akçay 2014

Tüner Önen 2008

Ümit 1996 phia. Michigan 1998.

J. Schäfer, Phaselis. Beiträge zur Topographie und Geschichte der Stadt und ihrer Häfen. Tübingen 1981.

N. Tüner Önen - A. Akcay, "Phaselis Antik Kentinin Su Teminine İlişkin Gözlemler ve Digital Teknolojinin Epigrafi Çalışmalarına Katkısı”. MJH IV/2 (2014) 279-292. http://dx.doi.org/10.13114/MJH.201428446

N. Tüner Önen, Phaselis Antik Kenti ve Teritoryumu. Yayınlanmamış Doktora Tezi, Akdeniz Üniversitesi. Antalya 2008.

O. Ümit, Phaselis Tarihsel Su Iletimi. Yayınlanmamış Diploma Çalışması, Pamukkale Üniversitesi. Denizli 1996. 